\title{
Single-incision Laparoscopy-assisted Appendectomy in the Pediatric Age Group: Our Experience
}

\author{
Charu Tiwari ${ }^{1}$, Hemanshi Shah ${ }^{2}$, Gursev Sandlas ${ }^{3}$, Neha Sisodiya Shenoy ${ }^{4}$, Suraj Gandhi ${ }^{5}$
}

\begin{abstract}
Background:Various methods of laparoscopic appendectomy have been described in children. We present the data of 50 children who underwent interval appendectomy at our institution by transumbilical single-incision laparoscopy-assisted appendectomy (SILAA).

Materials and methods: Fifty patients $<12$ years from June 2011 to June 2017 with inclusion criteria $<12$ years of age who were admitted with clinical features of acute appendicitis of $>24-48$ hours' duration; had abdominal ultrasound (USG) with appendicular diameter of $>10$ mm and good clinical response to initial management by intravenous antibiotics within 24-48 hours of admission were retrospectively analyzed. They underwent SILAA after 6 weeks. Under general anesthesia, an infraumbilical incision was made and umbilical tube was identified. A 5 $\mathrm{mm}$ camera port was inserted by open Hassan's technique. After visualizing the appendix, another incision was made adjacent to the port site on the left and a $5 \mathrm{~mm}$ instrument was introduced through this. The appendix was freed, mobilized, and delivered through the incision. Appendectomy was completed extracorporeally.

Results: The average age at presentation was 9.3 years. There were 18 females and 32 males. Two patients required conversion to open procedure in view of extensive adhesions and a short retrocecal appendix which was difficult to mobilize and exteriorize through umbilicus. The mean operating time was 30 minutes. There were no complications.

Conclusion: Single-incision laparoscopy-assisted appendectomy combines the advantages of both laparoscopic and open appendectomy and offers reduced operative time and less complications and reduced surgical costs in pediatric age group.

Keywords: Appendectomy, Laparoscopy, Pediatric, Single incision.

World Journal of Laparoscopic Surgery (2020): 10.5005/jp-journals-10033-1406
\end{abstract}

\section{INTRODUCTION}

Appendiceal pathology accounts for approximately $15-20 \%$ of all abdominal surgical emergencies in the pediatric age group. ${ }^{1-3}$ It has been regarded as the commonest indication for appendectomy in pediatric patients. ${ }^{1,4,5}$ Appendectomy is performed by various techniques, such as open, laparoscopic assisted, laparoscopic multiport, and single-incision laparoscopic approach. ${ }^{6}$ Laparoscopic appendectomy has been accepted as the gold standard for the management of appendicitis in children; its advantages over open appendectomy being less surgical trauma, less postoperative pain, fewer postoperative infections, shorter hospitalization, better cosmesis, and earlier recovery. ${ }^{7}$

The conventional laparoscopic appendectomy uses three ports for appendectomy. Appendectomy by a single incision is a further evolution toward minimally invasive surgery. ${ }^{6}$ We present the data of 50 children who underwent interval appendectomy at our institution by transumbilical single-incision laparoscopy-assisted appendectomy (SILAA).

\section{Materials and Methods}

We present our experience with SILAA in 50 pediatric patients $<12$ years from June 2011 to June 2017.

Inclusion criteria were children $<12$ years of age who were admitted with clinical features of acute appendicitis of $>24-48$ hours' duration; clinical evidence of acute appendicitis, abdominal ultrasound (USG) with appendicular diameter of $>10 \mathrm{~mm}$, and good clinical response to initial management by intravenous antibiotics within 24-48 hours of admission.

\footnotetext{
${ }^{1}$ Department of Paediatric Surgery, All India Institute of Medical Sciences, Raipur, Chhattisgarh, India; Department of Paediatric Surgery, Topiwala National Medical College and BYL Nair Hospital, Mumbai, Maharashtra, India

${ }^{2-5}$ Department of Paediatric Surgery, Topiwala National Medical College and BYL Nair Hospital, Mumbai, Maharashtra, India

Corresponding Author: Hemanshi Shah, Department of Paediatric Surgery, Topiwala National Medical College and BYL Nair Hospital, Mumbai, Maharashtra, India, e-mail: hemanshisshah@gmail.com

How to cite this article: Tiwari C, Shah H, Sandlas G, et al. Singleincision Laparoscopy-assisted Appendectomy in the Pediatric Age Group: Our Experience. World J Lap Surg 2020;13(2):77-79.

Source of support: Nil

Conflict of interest: None
}

Patients who presented within 24-48 hours of onset of their symptoms, had uncomplicated appendicitis with appendicular diameter of 6-10 mm on USG, resolution of their symptoms with intravenous antibiotics within 24-48 hours of admission, and no recurrence of symptoms were excluded from this study. They were kept on vigilant follow-up. Patients presenting with appendicular perforation and abscess and having inadequate response to intravenous antibiotics within 24 hours of admission underwent emergency appendectomy and therefore excluded from this study.

All patients with acute abdominal pain with clinical diagnosis of acute appendicitis underwent abdominal USG to rule out complications, such as perforation or abscess. Appendicular diameter was assessed on USG. In equivocal cases, computerized

(-) The Author(s). 2020 Open Access This article is distributed under the terms of the Creative Commons Attribution 4.0 International License (https://creativecommons. org/licenses/by-nc/4.0/), which permits unrestricted use, distribution, and non-commercial reproduction in any medium, provided you give appropriate credit to the original author(s) and the source, provide a link to the Creative Commons license, and indicate if changes were made. The Creative Commons Public Domain Dedication waiver (http://creativecommons.org/publicdomain/zero/1.0/) applies to the data made available in this article, unless otherwise stated. 
tomography was performed. Intravenous antibiotics were administered. All patients were clinically monitored for 24 hours for resolution of clinical signs (vomiting, fever, tachycardia, right iliac fossa tenderness). Patients showing clinical response within 24 hours were offered SILAA after 6 weeks.

Under general anesthesia, in supine position with the patient catheterized and strapped to the operating table, an infraumbilical skin fold incision was made and deepened. Umbilical tube was identified and a $5 \mathrm{~mm}$ camera port was inserted by open Hassan's technique. Capnoperitoneum was created and the pressure was maintained between $8 \mathrm{~mm} \mathrm{Hg}$ and $10 \mathrm{~mm} \mathrm{Hg}$. Appendix was visualized. Another incision was made adjacent to the port site on the left and a $5 \mathrm{~mm}$ instrument was introduced through this. Appendicular adhesions were dissected and appendix was freed. If necessary, a third incision was made to introduce an additional instrument to aid dissection. The tip of the appendix was held by a grasper and delivered through the infraumbilical incision (Fig. 1). Appendectomy was completed extracorporeally. The incision was then closed in layers. Skin was closed with subcuticular sutures.

\section{Results}

A total of 50 pediatric patients underwent appendectomy with interval SILAA procedure. The average age at presentation was 9.3 years. There were 18 females and 32 males. All patients had clinical symptoms of acute appendicitis and responded to intravenous antibiotics. They were discharged after the resolution of the acute phase and underwent interval appendectomy after 6 weeks.

Only two patients required conversion to open procedure in view of extensive adhesions and a short retrocecal appendix which was difficult to mobilize and exteriorize through umbilicus.

The mean operating time was 30 minutes. The average length of postoperative hospital stay was 24-36 hours. There were no postoperative complications (Fig. 2).

\section{Discussion}

After its first description by Semm in 1983, ${ }^{8,9}$ the conventional threeport laparoscopic appendectomy has gained worldwide acceptance

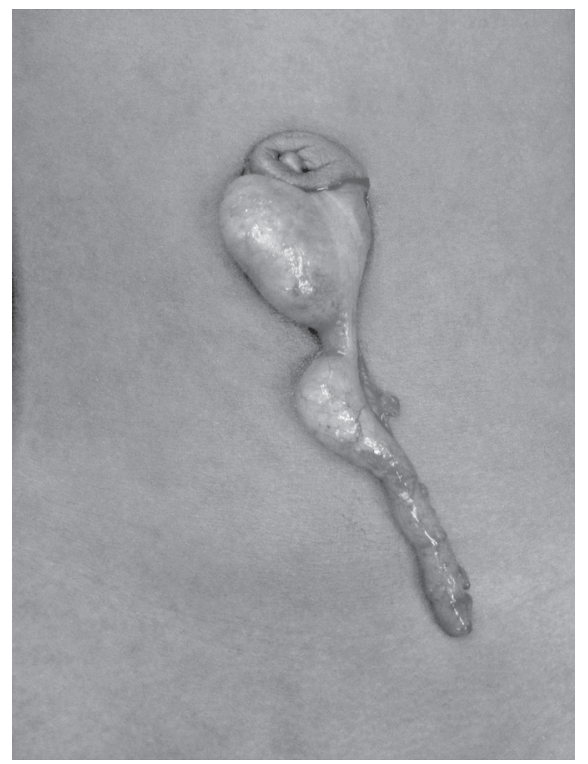

Fig. 1: Intraoperative image shows the appendix with part of cecum delivered through the infraumbilical incision among the pediatric surgeons. ${ }^{8}$ This technique has been evolving since then and there have been several modifications in order to achieve better cosmetic results, reduction in costs, shorter recovery period, and less hospital stay. ${ }^{8,10}$ These newer techniques are appendectomy by laparoscopy-assisted approach, two-port laparoscopic approach, transumbilical single-port laparoscopic conventional appendectomy, and transumbilical single-incision laparoscopy-assisted approach. 8,10

Single-incision and single-port laparoscopic appendectomy uses all three ports introduced through the infraumbilical incision and appendectomy is performed as in the conventional three-port manner by performing endocorporeal laparoscopic appendectomy. The single-port laparoscopic appendectomy is a recent advance which uses a singleport with three or four internal lumens. However, it requires special modified instruments-the single-incision port, curved instruments, and expertise; this ultimately increases the cost of surgery, especially in developing countries. ${ }^{6}$ The disadvantages of both these procedures as reported in the literature were longer operating time, clashing of instruments, ${ }^{11}$ and increased cost of surgery $i^{12,13}$ the added disadvantage being cost of new instruments.

Single-incision laparoscopy-assisted appendectomy utilizes the umbilical incision to introduce a camera port and another conventional instrument to exteriorize the appendix through the umbilicus followed by extracorporeal appendectomy. It has advantages of better intra-abdominal visualization, less postoperative morbidity, and good cosmetic outcomes. ${ }^{8}$ It is a safe, minimally invasive approach for interval appendectomy. It is a suitable surgical procedure for training laparoscopic abilities and also has low instrumentation requirements. ${ }^{8}$ The procedure can be performed with the same conventional laparoscopic instruments avoiding the cost of new instruments.

This procedure was first described by Valla et al. in 1999 as umbilical one-puncture laparoscopy-assisted appendectomy and combines the advantages of laparoscopic surgery with those of open surgery. ${ }^{8,14}$ Petnehazy et al. have suggested SILAA to be a better approach for appendectomy in obese children as well. ${ }^{15}$

Moreover, in an interval appendectomy, the surgery is performed once peritoneal contamination has been resolved,

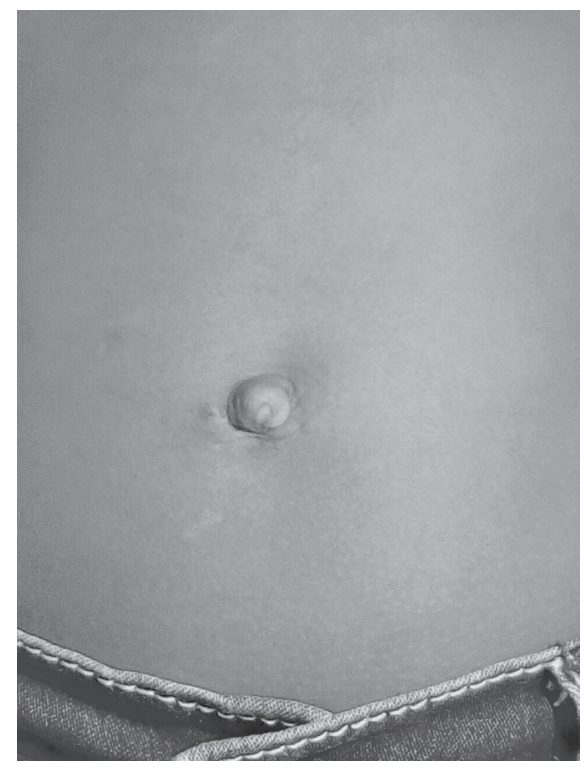

Fig. 2: Postoperative image of the umbilicus 
potentially resulting in fewer postoperative complications of bowel obstruction, wound infection, fistula formation, intraabdominal abscess, and bowel injury due to difficult dissection. ${ }^{16}$ It is more cost-effective as it requires less numbers of trocars and surgical instruments compared to conventional three-port laparoscopy. ${ }^{13,17,18}$ In children, the distance between appendix and umbilicus is shorter and the abdominal wall is more flexible making it easier to exteriorize the appendix through the umbilicus than in adults. ${ }^{19}$

The major disadvantage of SILAA is in terms of comfort and ergonomics. ${ }^{20}$ The ability to triangulate the instruments around the target is lost because all instruments and cameras are inserted through the same incision. ${ }^{20}$ However, with increasing exposure and experience with this technique, the operating time can be reduced significantly. ${ }^{20}$

\section{Conclusion}

Reduced-port and single-incision laparoscopic techniques have become popular in recent years for appendectomy. Single-incision laparoscopy-assisted appendectomy combines the advantages of both laparoscopic and open appendectomy and offers reduced operative time, early postoperative recovery, shorter duration of hospital stay, less complications, and reduced surgical costs in pediatric age group.

\section{References}

1. Fall M, Gueye D, Welle IB, et al. Laparoscopic appendectomy in children: preliminary study in paediatric hospital Albert Royer, Dakar. Gastroent Res Pract 2015;2015:878732. DOI: 10.1155/2015/ 878372.

2. Stevenson RJ. Chronic right-lower-quadrant abdominal pain: is there a role for elective appendectomy? J Pediatr Surg 1999;34(6):950-954. DOI: 10.1016/S0022-3468(99)90766-2.

3. Styrud J, Eriksson S, Nilsson I, et al. Appendectomy vs antibiotic treatment in acute appendicitis. A prospective multicenter randomized controlled trial. World J Surg 2006;30(6):1033-1037. DOI: 10.1007/s00268-005-0304-6.

4. Podevin G, Barussaud M, Leclair MD, et al. Appendicitis and appendicular peritonitis in children. EMC-Pediatrie 2005;2(3):211-219. DOI: 10.1016/j.emcped.2005.07.001.

5. Rai R, Chui CH, Sai Prasad TR, et al. Perforated appendicitis in children: bene tsof early laparoscopic surgery. Ann Acad Med Singap 2007;36(4):277-280.

6. Uday SK, Venkata Pavan Kumar CH, Bhargav PRK. A technique of single-incision laparoscopic appendectomy using conventional multiport laparoscopic instruments (SILACI): preliminary experience of 32 cases. Indian J Surg 2015;77(Suppl 3):S764-S768. DOI: 10.1007/ s12262-013-0996-z.

7. Donmez T, Hut A, Avaroglu H, et al. Two-port laparoscopic appendectomy assisted with needle grasper comparison with comparison with conventional laparoscopic appendectomy. Ann Surg Treat Res 2016;91(2):59-65. DOI: 10.4174/astr.2016.91.2.59.

8. Gupta RK, Gupta A, Kothari P, et al. Transumbilical laparoscopicassisted appendectomy: a safe and useful technique for interval appendectomy in paediatric population. J Minim Invasive Surg Sci 2014;3(3):et4365.

9. Semm K. Endoscopic appendectomy. Endoscopy 1983;15(2):59-64. DOI: 10.1055/s-2007-1021466.

10. Coletta LAD, Gil BZ, Zanatto RM. Minilapaparoscopic appendectomy. Arq Bras Cir Dig 2016;29(1):53-56. DOI: 10.1590/01026720201600010014.

11. Ostlie DJ. Single-site umbilical laparoscopic appendectomy. Semin Pediatr Surg 2011;20(4):196-200. DOI: 10.1053/ j.sempedsurg.2011.05.003.

12. Stylianos S, Nichols L, Ventura N, et al. The "all-in-one" appendectomy: quick, scarless, and less costly. J Pediatr Surg 2011;46(12):2336-2341. DOI: 10.1016/j.jpedsurg.2011.09.029.

13. Visnjic S. Transumbilicallaparoscopically assisted appendectomy in children: high-tech low-budget surgery. Surg Endosc 2008;22(7):16671671. DOI: 10.1007/s00464-007-9680-3.

14. Valla J, Ordorica-Flores RM, Steyaert $\mathrm{H}$, et al. Umbilical one-puncture laparoscopic-assisted appendectomy in children. Surg Endosc 1999;13(1):83-85. DOI: 10.1007/s004649900906.

15. Petnehazy T, Saxena AK, Ainoedhofer H, et al. Single-port appendectomy in obese children: an optimal alternative? Acta Paediatrica (Oslo, Norway: 1992) 2010;99(9):1370-1373. DOI: 10.1111/j.1651-2227.2010.01791.x.

16. Bae SU, Jeong WK, Baek SK. Single-port laparoscopic interval appendectomy for perforated appendicitis with a periappendiceal abscess. Ann Coloproctol 2016;32(3):105-110. DOI: 10.3393/ ac.2016.32.3.105.

17. Go DY, Boo YJ, Lee JS, et al. Transumbilical laparoscopic-assisted appendectomy is a useful option for Paediatric uncomplicated appendicitis: a comparison with conventional 3-port laparoscopic appendectomy. Ann Surg Treat Res 2016;91(2):80-84. DOI: 10.4174/ astr.2016.91.2.80.

18. Deie K, Uchida H, Kawashima H, et al. Singleincisionlaparoscopicassisted appendectomy in children: exteriorization of the appendix is a key component of a simple and costeffective surgical technique. Pediatr Surg Int 2013;29(11):118791. DOI: 10.1007/s00383-013-3373-x.

19. Ohno Y, Morimura T, Hayashi S. Transumbilical laparoscopically assisted appendectomy in children: the results of a singleport, singlechannel procedure. Surg Endosc 2012;26(2):523-527. DOI: 10.1007/ s00464-011-1912-x.

20. Kumar A, Sinha AN, Deepak D, et al. Single incision laparoscopic assisted appendectomy: experience of 82 cases. J Clinical Diag Res 2016;10(5):PC01-PC03. DOI: 10.7860/JCDR/2016/8146.7775. 